\title{
LA INTENCIÓN RELIGIOSA DEL LAZARILLO
}

La intención religiosa del Lazarillo ha sido investigada hasta ahora, de manera sistemática, desde supuestos ideológicos preestablecidos y siempre al servicio de un objetivo particular: el desenmascaramiento de la anonimia. Las tesis de un autor converso -A. Castro ${ }^{1}$, Gilman ${ }^{2}-$, iluminista -M. J. Asensio 3 -, o erasmista-iluminista - Márquez Villanueva - por citar sólo las clasificaciones y autores más representativos, han sido ya sustancialmente cuestionadas en su dimensión socio-histórica por críticos tan autorizados como Marcel Bataillon ${ }^{5}$ - Eugenio Asensio ${ }^{6}$. Consideradas desde una perspectiva estrictamente lingüística, se advierte en seguida que se apoyan, invariablemente, en segmentos extractados del contexto general -a veces, incluso, del parcial- e interpretados por referencia comparativa con muy escasos textos de autores contemporáneos. Tal metodología, además de ser acrítica, conduce a palmarias extrapolaciones ell relación con la estructura orgánica de la obra, y a no pocas contradicciones internas respecto de las tesis sustentadas.

1 Amírico Castro, Perspectiva de la novela picaresca. RBAM, I935, XII, pp. I23-1 38; recogido, con adiciones, en Hacia Cervantes. Madrid, Taurus, 3. a edic., 1967, pp. I I 8-I 42.-Adición en 1957 al prólogo de la edic. del Lazarillo por HrSSE y Wri.IAMs (1948); recogida, igualmente, en Hacia Cervantes, pp. I43-I66.

2 Stepinen GHMan, The Death of Lazarillo de Tormes. PMLA, 1966, LXXXI, pp. $149-166$.

3 M. J. Asensio, La intención religiosa del Lazarillo de Tormes. $H R$, I959, XXVII, pp. 78-102.-Más sobre el Lazarillo de Tormes. HR, 1960, XXVIII, pp. 245-250.

- Hrancisco MRrquez Vili,anUeva, La actitud espiritual del Lazarillo de Tormes en Espiritualidad y Literatura en el Siglo XVI. Madrid, Alfaguara, 1968, pp. 67-137.

- Marctir Batairion, Evasino y España. México, Fondo de Cultura Económica, 2. edic., 1966, pp. 609-6I I.-Novedad y fecundidad del Lazarillo de Tormes Salamanca Anaya, I968, pp. I-25. Los cristianos nuevos en el auge de la literatura picaresca, recogido en Picaros y Picaresca. Madrid, Taurus, 1969, pp. 21 5-243.

- IUUGenio ASENSIO, El erasmismo y las corrientes espirituales afines. RFE, 1952, XXXVI, pp. 3I-99.-La peculiaridad literaria de los conversos. AEM, I967, 
Se impone, pues, ante todo, precisar, mediante un amplio cotejo de autores y fuentes, el sentido de uso del léxico religioso y moral del Lazarillo. Mi estudio abarca, integras, las siguientes obras: La Celestina ${ }^{1}$, la Propalladia ${ }^{2}$, La Lozana Andaluza ${ }^{3}$ y el Viaje de Turquia 4 . Obras todas ellas que el anónimo autor tuvo que conocer y que reflejan diversos estratos del habla popular. La confrontación de los segmentos religiosos del Lazarillo entre sí contribuirá a determinar los matices morfosemánticos de presentación del material tópico y definirá, a la vez, las lineas de convergencia hacia el uúcleo siguificativo central de la obra ( 4 bis).

El hombre y su caso

La preexistencia folklórica de un personaje denominado Irazarillo no está en modo alguno documentada. En efecto, casi todos los críticos desechan como irrelevante la alusión obscena de La Lozana andaluza ${ }^{5}$. Iil nombre de Lázaro evoca, indudablemente, resonancias bíblicas. Cono se recordará, en el evangelio aparecen dos: el hermano de Marta y María (Jo. II, I-45) y el mendigo lacerado (Luc. I6, I9-3I). Yakov Malkiel ha puesto de relieve cómo el primero, que desempeña un papel muy importante en la temática de la pintura occidental, apenas si deja huella en la literatura. Del mendigo, por el contrario, se detectan bastautes muestras, sobre todo en la fraseologia y paremiología españolas ${ }^{6}$. El maestro Correas recoge en su Vocabulario los dichos «Por Lázaro lazeramos, por los Ramos biell andamos» y «Más pobre que Lázaro»? En este contexto de fijación semántica folklórica, el bautizo onomástico

1 Sigo la edic. de JUlio CEJADOR. Clásicos Castellanos. Madrid, 1968.

2 Sigo la edic. de JOSEPH E. GIILET, Propalladia and other Works of Bartolome de Torres Naharro. 3 vols, Bryn Mawr, Pennsylvania, I943.

3 Sigo la edic. de Bruno Daninant. Clásicos Castalia, rg69.

- Sigo la edic. de AnTonio G. Solarinde. Colección Universal de Calpe, I9r9.

4h. Utilizo como base de cotejo la edicibu crítica de Jost CASo GonzArEZ (Anejo XVII del BRAE. Madrid, x967).

- Cf. MARfa ROSA LIDA, Función del cuento popular en el Lazarillo de Tormesı. Actas del I Congreso Internacional de Hispanistas, Oxford, I964, p. 350; y FraNcisco Rrco. Introducción a la clic. del Lazarillo. La Novela picaresca española. Barcelona, Planeta, I967, p. IXVY y s.

- Yakov MLAKIEI, La familia léxica lazerar, laz(d)rar, lazeria. NRFH, I952, VI, 11um. 3, p. 273 y ss.

7 G. Corress, Vocabulario de refranes. Madrid, 1924, pp. 403 y 296. 
del protagonista de nuestra novela puede connotar, ya de entrada, una triste suerte de indigencia. Sólo eso. Quiero decir que, a mi juicio, no cabe ampliar la interpretación en el sentido de adecuarla con la narración evangélica. Esta, de mayor alcance social, contrasta la pobreza del mendigo con la indiferencia egoísta del rico epulón, al que ni de lejos se parece ninguno de los amos de Lázaro. Pero el propio Yakov Malkiel apunta, además, que, en el folklore español por descuido y deliberadamente en la literatura del xvir, hubo mucha confusión entre los dos Lázaros. Góngora, por ejemplo, en un texto que hace mucho a nuestro caso, escribe: "Fue mi resurrección la maravilla/que de Lázaro fue la vuelta al mundo; / de suerte que ya soy otro segundo / Lazarillo de Tormes en Castilla" ${ }^{1}$. ¿Da pie el Lazarillo a esta doble tipificación? Sin ir tan remotamente lejos como Gilman quiere llevarnos ${ }^{2}$, pienso que sí. No me parece, en efecto, insignificante que el autor haga que los dias que Lazarillo pasa inconsciente, medio muerto tras el garrotazo del cura de Maqueda, sean precisamente tres, y lo exprese, en concreto, por boca de Lázaro, haciendo alusión al mito de Jonás y la ballena, uno de los símbolos prefigurativos utilizados en el V. T. para referirse a la resurrección de Cristo ${ }^{3}$. La novela sería, según eso, la historia de un hombre constantemente lacerado, en cuerpo y alma 4 , que resucita de las sucesivas lacerias hasta afirmarse en la cumbre de toda fortuna. In seguida veremos qué papel desempeña esta primera conclusión parcial en la integración de signos de convergencia.

Lázaro Carreter ha documentado distintas versiones literarias del tema del marido complaciente, con un clérigo como tercero en concordia: desde el punto de vista de la mujer adúltera (Rodrigo de Reinosa), del clérigo (Diego Sánchez de Badajoz), del autor, en fin, (Sebastián de Horozco) ${ }^{5}$. Todos estos casos recortan mucho el alcance intencional del "caso» concreto que Lázaro de Tormes relata por extenso a "vuestra merced». En Torres Naharro encuentro precedentes temáticos que

1 Obras completas, Edic. de Foulchit-DiLbosc, Vol. I, p. i 76 (Cf. y. DLALKIEL, op. cit., p. $2 \mathrm{II}$, nota ad calcem).

2 Según él, los tres primeros capítulos constituyen una parodia del mito cristiano de muerte y resurrección. E. AsIsnsio califica la interpretación de Gilman como el juego del "adivina adivinanza" (Cf. La peculiaridad...", p. 34I).

3 Mat. I2-40.

- Según Y. MaLkuir, en la gran mayoria de los casos olsservados "laz(d)rar» significa sufrir en el alma o en el cuerpo; en particular, sufrir un castigo infligido por Dios o los hombres. Otras veces significa, scncillamente, trabajar. Todos estos usos se dan en el Lazarillo. Op. cil., p. 267 y s.

- Mirnando LAzaro Caveritir, Construcción y sentido del Lazarillo de Tormes. Abaco, I, I969, p. 5 I y s. 
vienen a completar más de cerca, puesto que el "caso» aparece visto desde la perspectiva del cornudo, el cuadro de topoi esbozado. En el Introyto de la comedia Ymenea dice el protagonista:

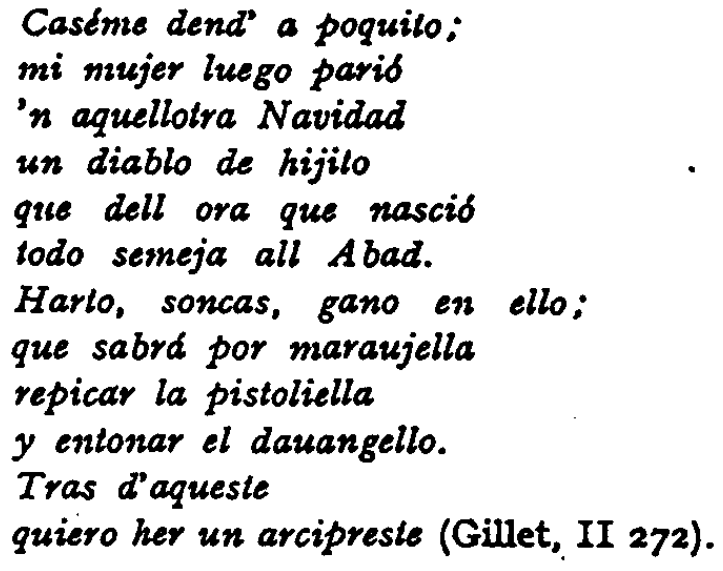

Más flagrante aún es el "caso" relatado en la Comedia Calamita. Jusquino, que quiere aprovecharse de la mujer de Torcazo, un semibobo complaciente, tras presentárscle como pariente, le pide:

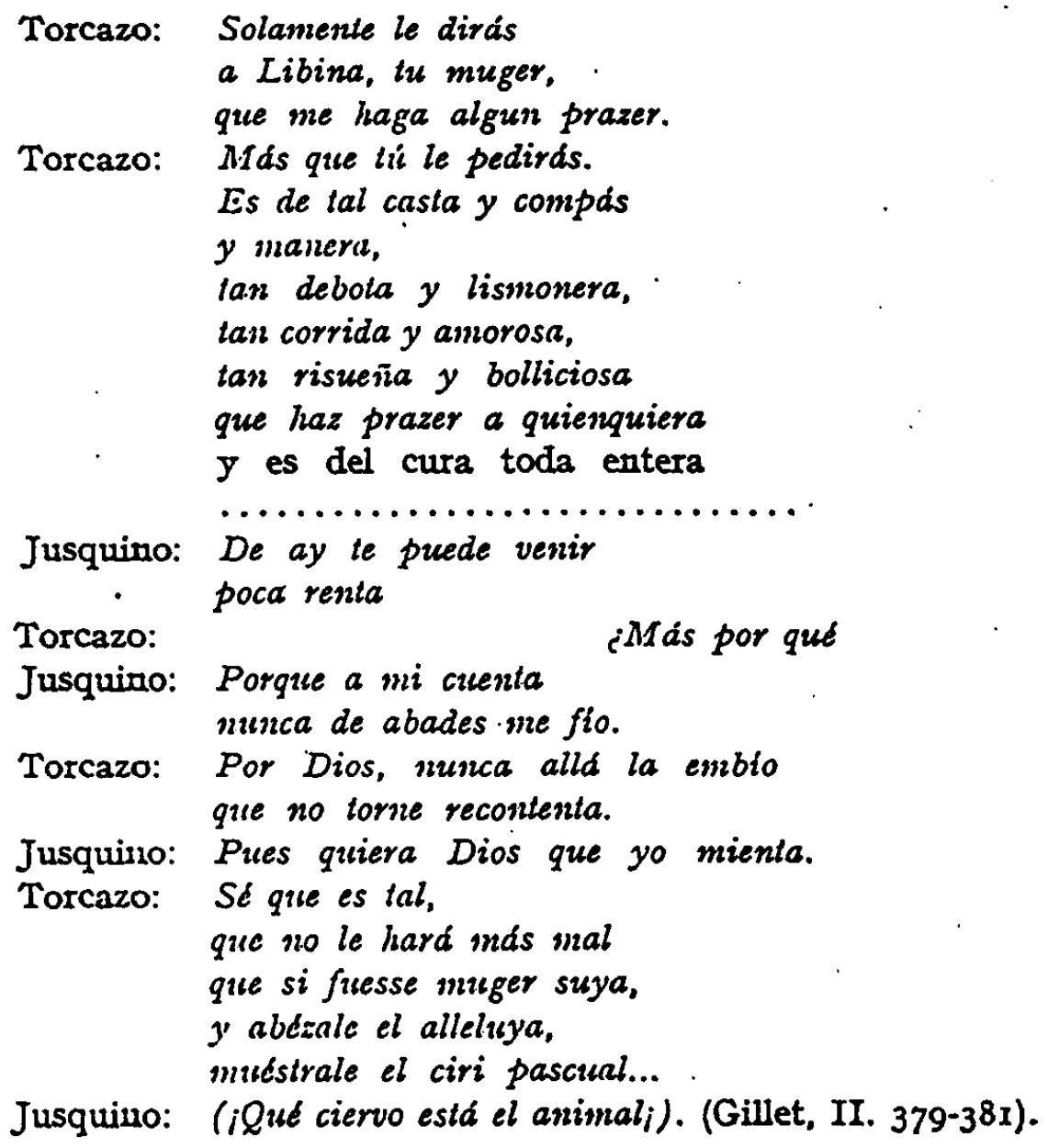

Jusquino: (iQué ciervo está el animali). (Gillet, II. 379-381). 
Al hablar de un tema tópico, no pretendo negar la abundancia de clérigos concubinos. El que la literatura lo aborde con tranquilidad y buena dosis de desparpajo indica que se trata de un hecho aceptado con tal serenidad, tan encajado, diría, en la mentalidad y convenciones de la época, que lo que hoy nos suena a denuncia irritada era leido y escuchado entonces con exultante regocijo. Claro que el autor del Lazarillo marca un paso adelante, señalando con el dedo un lugar y un tiempo bien concretos: Toledo, I525-I550. Andrea Navaggero visitó la ciudad imperial en I525 y testifica en su Viaje por España que "los amos de Toledo, y de las mujeres precipue, son los clérigos, que tienen hermosas casas y gastan y triumphan dándose la mejor vida del mundo, sin que nadie les reprendan ${ }^{1}$. Parece que el testimonio coincide en su planteamiento, y hasta en el tono verbal, con el Lazarillo. Pero conviene no precipitarse. De hecho, la Inquisición no se inmuta y deja sustancialmente intacto el Tratado VII. Los coetáneos devoran el libro y se desternillan de risa. Pienso, por ejemplo, en fray José de Sigüenza que, más que la novedad de la materia, admira en la obra "el singular artificio $y$ donairen, "la propiedad de la lengua castellana y el decoro de las personas que introduce» 2; o en Bartolomé Jiménez Patón, humanista riguroso, que vitupera el "lenguaje cașero y comúu», al que, según él, se reducen "los librillos de entretenimiento $y$ donaire, como el de Carnestolendas, Lazarillo de Tormes..." ${ }^{3}$. Reconiendo, a quien desee comprender un poco lo que hoy nos resulta tamaña incongruencia, la lectura de los. capítulos que los Sínodos y Concilios Provinciales del xvI dedican a la vida y costumbres de los clérigos، En ellos la atención se centra, preferente, en evitar que las barraganas vivan bajo el mismo techo o que los hijos adulterinos sean empleados en oficios de la misma parroquia. Sólo con la Reforma Tridentina empezarán a cambiar las cosas.

Dios en el Lazarillo.

Se puede sospechar a priori que el uso frecuentísimo del nombre de Dios en un libro de tantos quiebros -66 veces Dios; I5 Señor; I Señor Dios; I Su Majestad- no tiene un sentido intencional unívoco.

1 Viajes por España, Libros de Antaño, VII, Madrid. I879, p. 256 y s.

2 Cit. por M. BATAII,ION, Novedad..., p. 59 y s.

3 BARToromti Jimtenti PaTó, Elocuencia Española en Arte. Toledo, r604, Cit. por Antonio Viranova, Preceplistas de los siglos XVI y XVII. Historia. General de las Literaturas Hispánicas, Vol. III. Barcelona, 1953, p. 664. 
En efecto, las generalizaciones de diverso signo - uusado siempre con respeto" (Castro), "carente de significación religiosa" (Jones ${ }^{1}$ ), etc.se desmoronan en cuanto se inicia una clasificación de textos. Antes de entrar en ella y sobre la base de la confrontación total de las obras citadas, hay que descartar cualquier pertinencia significativa que pudiera derivar del dato numérico de uso: el lenguaje coloquial de la época estaba punteado a cada paso por referencias a la Divinidad.

\section{A) Lexicalización}

Un primer criterio de discernimiento analítico podría constituirlo la catalogación de expresiones o segmentos lingüísticos sociológicamente lexicalizados. La tarea no es fácil, puesto que el proceso de desemantización de una frase admite muchos grados y es, además, reversible, total o parcialmente. Se trata, por otra parte, de matices afectivos, perceptibles a veces con claridad en el contexto lingüístico, a veces - sólo traducidos en la entonación oracional. Cualquiera de las exclamaciones "iay, Dios!", "ipor Dios!", "ipor amor de Dios!n, "iDios me librel" - locuciones del tipo de "si Dios quiere", "Dios mediante»..., se registran habitualmente en el lenguaje coloquial de hoy con un grado casi absoluto de lexicalización; pero todas ellas conservan la potencialidad de ser utilizadas según su propio contenido semántico. Eñn el Lazarillo cncontramos, desde luego, bastantes casos de lexicalización absoluta:

a) exclamaciones: "i Oh gran Dios quién estuviera en aquella hora sepultado..." (I. 78); "no me fatigo mucho por comer, bendito Dios" (III. I04). El escudero repite a cada paso, como una muletilla, upor Dios»: "Sabrosísimo pan está - dixo- por Dios!» (III. I05), "Por Dios,. que me ha sabido como si no hobiera comido hoy bocadon (III. II4), "Por muestro Señor, cuanto ha que en ella vivo..." (III. II7), "Por Dios, si con él topasse (III. I23). "Por Dios, que está bueno el negocio», dicen, también, el alguacil y el escribano (V. I26).

b) juranentos: "Juraré yo a Dios que tú has comido las uvas tres a tres", dice el ciego (I. 75). He de poner aquí de relieve cómo Lazarillo no utiliza en sus juramentos esta fórmula; así, poco antes ha dicho: "y, aunque yo juraba no lo hazer con malicia" (I. 74). El escudero, a su vez, exclama: "...mas, joótotc a Dios" (III. I20). Lazarillo utiliza solamente "Dios es testigo..." (III. II5). Coutrasta tal actitud del niño y

1 R. O. Jonrs, Introduction a "La Vida de Lazarillo de Tormes", Col. Spanish Terts, Maucliester University Press. p. XXXV y s. 
adolescente con la de Lázaro adulto que jurará con menos miramientos.

c) "si a Dios plaze»: es, en sus distintas formas conjugadas, la expresión lexicalizada más frecuente. A veces tiene un sentido. equivalente a "ojalá». "Pluguiera a Dios que lo hubiera hecho», dice Lázaro refiriéndose al haberle trincado las narices al ciego (I. 79); "pluguiera a Dios que me demediara" (II. 84). Con significación propia, pero lexicalizada: "Pues estando en tal aflicción, cual plega al Señor librar de ella a todo fiel cristiano" (II. 88), "Plega a Dios que no me muerda, decía yo" (II. 96), "Pues ha tornado en su acuerdo, placerá a Dios no será nada" (II. 98), "Agora, pues, come pecador, que, si a Dios plaze, presto nos veremos sin necesidad" (III. II3), "Assi plega a Dios》, añade el escudero (III. I06).

d) "id con Dios»; "por amor de Dios»: son expresiones que, como la de "manténgaos Dios» que en seguida estudiaremos, analizadas en su objetiva significación directa, podrían parecer cargadas de intencionalidad crítica. Pero entran de lleno en el grupo de usos tópicos. Con un "Busca amo y vete con Dios» despide el ciego a Lazarillo (II. 99); "andá con Dios" es, según el escudero, la frase habitual de despedida de un servidor (III. I22). "Por amor de Dios" y "por Dios" van siempre referidos a la limosna y caridad: "le damos de comer lo que podemos - dicen las buenas vecinas-por amor de Dios" (III. I26); "Saqué unos pedazos de pan del seno, que me habían quedado de los de por Dios" (III. I04); "más vale pedillo por Dios que no hurtallo» (III. II2). En el sentido de caridad lo utilizan los feligreses del tratado $\mathrm{V}$, dirigiéndose al buldero: "por amor de Dios lo hiciesse» (V. I36).

En el empleo y frecuencia de estas fórmulas, aisladas o en su conjunto, no alcanzo a ver intencionalidad alguna estructural. Dicho de otro modo: no se trata de segmentos convergentes hacia el núcleo significativo de la obra, sino marginales a su desarrollo.

\section{B) Deslexicalización}

A lo largo de la novela el lector se encuentra con una serie de segmentos que, pertenecientes, de suyo, al acervo de lexicalizaciones coloquiales del xvr, están sometidos a un proceso de deslexicalización y recobran, total o parcialmente, su significado directo. Aquí nos movemos ya por el entramado de la construcción novelística.

a) las frases "confio en Dios", "espero en Dios" - como cercanas al "si a Dios plaze)-, y "Dios te gulic), como deseo de despedida, eran de uso tópico en la época. Pero, sin duda, en el Lazarillo acumulan indirectamente, por su situación, y aportan al contexto una carga espe- 
cífica de intención. A propósito de su padre, ladrón, dice Lazarillo: "Espero en Dios que está en la gloria" (I. 63). Por su parte, la madre «confíaba en Dios no saldría peor hombre que mi padre" (I. 66) y, en el momento del adiós, le da su bendición diciendo: "Procura de ser bueno y Dios te guín (I. 66). ¿Cómo no adivinar aquí uno de los polos de simetría ${ }^{1}$ que se va a cerrar con la referencia final al oficio regio 4en el cual el día de hoy vivo y resido a servicio de Dios y de vuestra merced (VII. I42) y la situación de marido complaciente, a quien con su mujer whace Dios mil mercedes" (VII. I 45)? Por algo la Inquisición, que, como he apuntado, respeta en sustancia el tratado, suprime, precisamente, la expresión sa servicio de Dios», que vendría a indicar: hasta aquí me ha guiado El, cumpliendo la confiada esperanza de mi madre.

b) "Mantenga Dios a vuestra mercedl». El escudero no acepta el saludo y Lázaro, deslexicalizándolo, pregunta: "¿Y no es buena manera de saludar un hombre a otro... decirle que le mantenga Dios...?...; por eso tiene tan poco cuidado de mantenerte, pues no sufres que nadie se 10 pida" (III. I2I). A los textos aducidos por A. Castro ${ }^{2}$, María Rosa. Lida ${ }^{3}$, y It. Rico ${ }^{4}$ en prueba del carácter tópico de este motivo y del juego de deslexicalización, quisiera añadir, por el interés de la fecha, los que se encuentran en el Viaje de Turquia. Allí dice Mátalascallando: «Pues el Dios te ayude, ¿yo de quién lo aprendí sino de vos, que en mi tierra a solos los que esternudan se les dice esa salutación?» (I. I9); Pedro de Urdemalas afirma: "Yo no pido, por cierto, limosna; y a trueco de no oir un "Dios te ayude» de quien sé me puede dar, lo hurtaría si pudiesse" (I. 40).

c) Las frases "Dios te (me) ayude», "Dios haya lástima de...", "Dios te lo dé», "Bucnas nucvas te dé Dios» aparecen deslexicalizadas: "Y ansí El (Dios) me ayude, como ello me parece bien" (III. II2), "Y mejor les ayusde Dios, que ellos dicen la verdad" (VII. I43), "Tanta lástima haya Dios de mi, como yo había de él» (III. II3); "Tal te la dé Dios», replicaba Lázaro al clérigo que le decía: «mejor vida tienes que el Papa» (II, 85); y al mismo clérigo que contaba nueve bodigos: unuevas malas te dé Dios» (II. 89).

Podemos preguntarnos ya qué tipo de función estructural desempeñan estas deslexicalizaciones. A mi juicio, es clara: tratan de introducir a Dios en la escena y acción de la novela como actor principal: la intervención divina se convierte, así, en uno de los ejes de desarrollo.

a Cf. Ldzaro Carretrar, Construcción...., pp. 64-69.

- Ilacia Corvantes, 1). 99.

- Función dol cucuto..., p. 357.

- Introduccion, p. 60, nota 86. 


\section{C) Dios ad usium Lazari}

Dios aparece como cooperador, in prosperis et adversis, a favor de Iázaro. Para cumplir el deseo de la madre - "Dios te guíe»-, llevándolo al buen puerto de «su servicio», no duda en remover obstáculos e inspirarle soluciones, aunque aquellas signifiquen la vida de una persona y éstas consistan en descalabrar, por apetito de venganza, a un ciego. Así, Lázaro atribuye la ofuscación del astuto ciego, que le hace ir de bruces contra el poste, a la prisa que llevaban uy, lo más principal, porque Dios le cegó aquella hora el entendimiento (fue por darme dél venganza)" (I. 8I). En los seis meses que pasa con el cura de Maqueda "veinte personas fallecieron... porque viendo el Señor mi rabiosa y continua muerte, pienso que holgaba de matarlos por darme a mi la vida" (II. 87). Ia ayuda divina le asiste de continuo. El calderero se convierte en un ángel enviado por Dios (II. 88), el Espíritu Santo le ilumina para robar (II. 87) y el mismo Dios hace que el cura, a la hora del recuento, no mire la oblada (II. 89). "Dios, que socorre a los afligidos", le sugiere la treta de los ratones como «un pequeño remedio»(II.gI). "La merced de Dios" le sana del descalabro del clérigo (III. Ior) y le hace topar con el escudero (III. I02). Por eso, Lázaro da gracias al Señor (ibid.). Si teme una reprimenda del escudero por la tardanza, "más mejor lo hizo Dios» (III. II2). Sabe que en el abismo de estrechez en que está sumido en la casa lóbrega y oscura, es Dios quien cumple su deseo de saciar el hambre (III. II3) y El quien abre la mano (III. II7). La protección de lo alto alcanza su mayor intensidad en el tratado VII. Lázaro confiesa paladinamente que se halla asentado en su "cason, porque "quiso Dios alumbrarme y ponerme en camino y manera provechosa" (VII. I4I); ha sido Dios el que le ha guiado a la "cumbre de toda buena fortunan: la holgada posición del ínfimo de los oficios, condicionada y honrada por la aceptación del juego de marido complaciente.

Nos apresuraríamos a calificar de blasfemo todo esto, si no conociéramos precedentes que documentan una cierta topicidad. Pienso, fundamentalmente, en La Celestina. Ia vieja tercera presume de que, "a Dios gracias", ella ha sido la "corredora del primer hilado de las vírgenes de la ciudad" (I. Auto III. I33) y confía en que, "si a Dios ha plazido», no será Melibea la primera que se le escape» (I. Auto IrI. I38). Aunque es vieja, ella nunca se ha cansado de hacer el amor, y usabe Dios mi buen desseo" (I. Auto III. I38): "Dios conoce mis limpias entrañas, mi verdadero amor" (I. Auto V. I62). Cuando la brava Melibca se escandaliza y rebela ante las proposiciones que Celestina medio le 
sugiere, ésta contesta rápida: «Por Dios, señora, que me dexes concluyr mi dicho... I verás cómo es todo más servicio de Dios que passos deshonestos» (I. Auto IV. I79). - Recuérdese que Iázaro califica su última situación como servicio de Dios-. Celestina incita a Areúsa a prostituirse, con el argumento de que "Por Dios, pecado ganas en no dar parte destas gracias a todos los que bien te quieren. Que no te las dio Dios para que pasasen en balde por la frescor de tu juventud" (I. Auto VII. 250). Calisto, por su parte, dice al oir tañer las campanas: "tañen a missa. Dáca mis ropas, yré a la Madalena. Rogaré a Dios aderece a Celestina e ponga en coraçón a Melibea mi remedion (II Auto VIII. Ig). Por fin, el movido diálogo del Auto XII plantea abiertamente el tema. Exclama Calisto: "Pues, o alto Dios, "¿cómo te podré ser ingrato que tan milagrosamente has obrado conmigo tus singulares maravillas? $\mathrm{Y}$ añade dirigiéndose a Melibea:” ¡O mi señora e mi bien todol. ¿Por qué llamas yerro aquello que por los sanctos de Dios me fue concedido? Rezando oy ante el altar de la Madalena, me vino con tu mensaje alegre aquella solícita mujer». Pármeno interrumpe: "iDesvariar, Calisto, desvariar!. Por fé tengo, hermano, que no es cristiano. Lo que la vieja traydora con sus pestiferos hechizos ha rodeado e fecho dize que los sanctos de Dios se lo han concedido e impetrado" (II. Auto XII. 85-88). Idéntico procedimiento aparece utilizado en La Lozana andaluza. En los comienzos de la novela nos encontramos con una escena de despedida que, aunque estructurada de modo diferente, in extenso, anticipa la del Lazarillo de su madre. Aquí la tía de Aldonza le recomienda: "Hija, sed buena, que ventura n'os faltará" (I. 38); y añade poco después: "nno os tiene Dios olvidada" (II. 39). Al igual que Lázaro tras el coscorrón, A1donza se siente sola y piensa: "Yo sé muncho; si agora non me ayudo en que sepan todos mi saber, será ningunon (V. 45 y s.). Al final de su vida se mantiene segura de que "mo me faltará la merced del Señon (XIII. I73). Podrían añadirse otros lugares literarios en que se atribuye a Dios la imaginación de un recurso de éxito en medio de la dificultad. Cito, por su semejanza léxica con el Lazarillo, el caso del Viaje de Turquia donde Pedro de Urdemalas cuenta que, ante la amenaza de muerte si no se hacía turco, «... volvíme al verdugo, alumbrado del Espiritu Sancto, que ya era la muerte tragada, y díjele: «Haz lo que te han mandado" (I. II5). El gesto de estoicismo le salva de la ejecución. Todos estos lugares han de condicionar la valoración de aquellos textos del Lazarillo en que Dios aparece "ad usum Lazari», como jefe de la familia picaresca, según la apreciación de Hans Jauss ${ }^{1}$.

2 Das mystiche Vokabulär rückt Uen Schelmenstreich in den Aspekt eines 
Conviene precisar aquí el grado de trascendencia de este Dios. Hablemos de la oración en el Lazarillo y de Lázaro orante. Son muchos los críticos que, siguiendo la lectura de las interpretaciones judaizante, erasmista o iluminista, adivinan en la novela un buscado contraste entre la oración de los estamentos populares, formulista, vocal, fuertemente impregnada de superstición, y la más pura, mental, interior de Lázaro. Ejemplos expresivos del primer modo abundan, sin duda, en el II tratado. El ciego tenía como "oficio» recitar oraciones por encargo estipendiado y a fé que en esto uera un águila: ciento y tantas oraciones sabía de coro... Decía saber oraciones para muchos y diversos efectos..." (I. 68). Lázaro elogia el empaque exterior con que el ciego cumple su cometido, horro de cualquier vibración religiosa y en fraude continuo. La verdad es que la descripción de esta religiosidad meramente oracional no constituye nada nuevo. So pretexto de ir a pedirle "una oración... que le dixeron que sabías de sancta Polonia para el dolor de muelas" (I. Auto IV. I8I y IgI), conecta la vieja Celestina con Melibea. Muy devotas son, también, en este sentido, según la Lozana, las putas de Zocodóver (XX. IOr). Las alusiones se tornan denuncias explícitas en el Viaje de Turquia. Habla Mátalascallando de los mendigos que "con sus voces ordinarias son a la puerta de la iglesia en la misa mayor y en las menores de persona en persona, que aún de la devoción que quitan tienen bien que restituir» (I. 2I). Todos estos casos y otros muchos que podrían aducirse, reflejan la conciencia social deformada de lo que vengo llamando un "Dios ad usum», al que puede manipularse mediante determinadas fórmulas eficaces - superstición mágica-: un Dios, en suma, escasamente trascendente. En el Viaje de Turquía encontramos repetidas veces defendida la actitud contraria. Es la que, por ejemplo, encarna Pedro de Urdemalas cuando confiesa que, en peligro de ser descubierto por los jenizaros, no tuvo uninguna cuenta con los pater nostres que rezaba, sino con solo estar atento a lo que decía»; y añade: "¿Luego pensais que para con Dios es menester rezar sobre taja?» I. 233 y ss.). ¿Se da algo semejante en el caso del Lazarillo? No alcanzo a verlo.

Seis veces alude Lázaro a su propia oración. Durante su permanencia con el clérigo, como quiera que en los mortuorios saciaba el hambre, "rogaba a Dios que cada día matasse el suyo" y así especifica que, al

Gnaderwieses und lässt Gott gleichsam als Komplizem des Schelmen erscheinen». H. R. JAUSs. Ursprung and Dedeutung der Ich-Form in Lazarillo. RJ, 19.57, p. 299. Cf. GILMAN, op. cit., p. I58. 
dar la extremaunción, "no era el postrero en la oración, y con todo mi coraçón y buena voluntad rogaba al Señor no que le echasse a la parte que más servido fuesse, como se suele decir; mas que lo llevasse de este mundo" (II. 86 y s.). Cuando el calderero inicia su tarea, Lázaro le ayuda con sus uflacas oraciones" (II. 88) y, en tanto el clérigo cuenta y recuenta los bodigos, en umi secreta oración y devociones y plegarias decía: ¡Sant Juan y ciégale!n (II. 89). Por dos veces su oración es de acción de gracias: en el momento de topar con el escudero (III. I08) y cuando éste logra un real (III. II8). Por último, al comprobar que el hidalgo, lejos de remediar su angustiada situación, la empeora, pide "a Dios muchas veces la muerte" (III. I08). Hay que añadir a esto dos soliloquios oracionales. Uno referido a la brevedad de los placeres de la vida y a las continuas asechanzas que padecemos (II. gr) y el otro de reflexión sobre los padecimientos de la honra: "cuántos de aquestos... padecen... lo que por Vos no sufrirían (III. IIO). Pues bien, sólo en este último Lázaro sale fuera de la órbita de concepción de un "Dios ad usumn. Iin cl resto de los casos, incluso en la acción de gracias, el impulso oracional revierte y se cierra sobre el yo y sus necesidades inmediatas concretas. A esto le empujaba la vida misma. Era, también, lo que le enseñaban sus maestros. Lo revela el propio Lázaro al contar su destreza en el pordioseo: "Con basa y enferma voz y inclinadas mis manos en los senos, puesto Dios ante mis ojos y la lengua en su nombre, comienço a pedir pan.... (III. II2). Podría pensarse en una vivencia religiosa. Pero no nos dejemos engañar: está imitando al ciego, quien, "después de Diosn, le dio la vida (I. 67) ${ }^{1}$. El mismo nos lo descubre: "como yo este oficio le hubiese mamado en la leche, quiero decir que con el gran maestro, el ciego, lo aprendí, tan suficiente discípulo salí que...) (loc. cit.).

\section{La devoción o el engaño a los ojos}

- Por fuerza debo referirme aquí, en un análisis del plano léxico, a los argumentos sobre los que suele alzarse la tesis de un Lázaro orante espiritual, interior. La afirmación de Márquez Villanueva de que, a lo largo de los tres primeros tratados, vemos a Lazarillo "en sufrida y piadosa comuuicación con Diosn, no aparece documentada. Sin duda él no ignora la enorme fluctuación semántica del léxico religioso del xVI,

1 Quisiera notar que esta expresión es tópica. La vieja Celestina dice: "Yo le fize hombre, de Dios en ayuson (I, Auto VII, 233). 
puesta de manifiesto por Margherita Morreale ${ }^{1}$. Ni una sola vez se encuentra en la novela el vocablo "piedad" que, por lo demás, es usado en la época con significación casi exclusiva de caridad, compasión y lástima, ligado, sobre todo, con la voluntad y el afecto ${ }^{2}$. Pero, lo que es más importante, tampoco se hallan datos de asimilación de la "pietas" erasmiana, la piedad ilustrada, que, según Alfonso de Valdés, consiste en un conocimiento de Dios no por ciencia, sino por experiencia y revelación ${ }^{3}$. Márquez, además de aludir al desinterés de Lázaro por los actos de culto - punto que contemplaré más adelante-, aduce como prueba clara de una "bien definida oración mental de Lázaro» el texto: "y en mi secreta oración y devociones y plegarias" (II. 89), "cuyo uso -añade- contrasta con el que se hace de la vocal como simple artificio para medir el tiempo - -ry en dos credos le hice invisible»-》(II. 89). He de notar que esto último constituye un topos coloquial, aún hoy, para indicar la rapidez de una acción; en la literatura del Xvi se da abundante casuística: en la Tincllaria, por ejemplo, lecmos: "querićndolo vos pagar / cuantes quc un credo passel ${ }^{4}$. Iin cuanto al texto del tratado II, ¿es lícito interpretar como miental una oración que -léase íntegra la frase- desemboca en una petición tan concreta como "iSant Juan, y ciégale!» (II. 89)? Desde luego que no. El adjetivo "secreta» que parece sugerir interioridad, 10 encontramos aplicado en La Celestina a las prácticas piadosas. Dice Celestina: "E aquestas en tiempo onesto, como estaciones, processiones de noche, missas del gallo, missas del alua é otras secretas denociones. Muchas encubiertas vi entrar en su casa» (I. Auto I. 7I). Melchor Cano destaca en su Censura de los Comentarios de Carranza el carácter quietista y aún fatalista de la oración de los alumbrados, quienes uno pedían cosa particular a Dios sino fiat volintas tua y entendían que así en los males como en los bienes, porque tenían por perfection conformarse con la voluntad de Dios, aunque los quisiese llevar al infierno" ${ }^{5}$. Estamos en los antípodas del texto del Lazarillo

1 ¿Devoción o piedad? Apuntaciones sobre el léxico de Alfonso y Juan de Valdés, $R P F$, 1956, VII, pp. 365-388.

2 "Usando vos de piedad y misericordia", dice Pedro de Urdemalas al fraile del Monte Athos (Viaje. I. 248). Y Celestina: "Que, pues en tu mucha virtud me faltó piedad... Pero ya sabes que el deleyte de la venganza dura un momento y el de la misericordia para siempre" (I, Auto IV, I8I y s.).

3 Cf. M. MORREALE, Op. cit., p. 377.

- GIL,IIT, II, 252.

- Fermfn Cabalitero, Vida del Ilmo. Melchor Cano. MLadrid, i871, Apéndice 53, p. $55^{8}$ (Cf: Antonto MírQuez. Origen del iluminismo. Revista de Occidente, junio I968, p. 328. Iin prensa este artículo, aparece el libro del mismo autor, Los alumbrados. Origenes y filosofia (1525-I 559). Madrid, Taurus). 
que comentamos. Más todavía. Entiendo que es precisamente en él donde se confirma de manera expresa la inserción del protagonista en el mundo oracional inmanente de un "Dios ad usum». En virtud de la aludida fluidez semántica, Lázaro yuxtapone, en identidad, los términos: usecrcla oración, devocioncs y plegariasu. Se trata de una expresión. de redundancia, gemela en la estructura a aquella de Calixto: $S$ Sin dubda encomparablemente es mayor tal galardón, que el seruicio, sacrificio, deuoción é obras pías, que por este lugar alcançar tengo yo a Dios. offrescido (I. Auto I. 32). Margherita Morreale afirma en su monografía que, durante das décadas más agitadas del xvI y en los ámbitos. de mayor fermentación espiritual, el término devoción padece un oscu-. recimiento: le acompañan voces peyorativas como ceremonias y ceremoniático, superstición, escrúpulo». ¿Qué ocurre en los estratos menos. cultivados espiritualmente?. Una búsqueda minuciosa en las cinco fuentes que constituyen la base de mi estudio, permite fijar las siguientesconclusiones scmasiológicas: I. Divocrón, singular. Poco usado: A) sentido de fervor: los mendigos "aun de la devocion que quitan tienen bien que restituir (Viajc. I. 2I); si los peregrinos de Sant Juan deOrtega no obtienen gracia, userá por la poca devoción que llevan» (Viaje. I. 78). B) intensidad de sentimiento o afectos: se utilizaba constantemente en sentido profano; así leemos en la II de las Epistolas familiares de la Propalladia: " $Y$ es razón / pues con tanta devoción tu querer en mi se pinta / que quédasse el cora fón / de la color de la tinta" / (Gillet I. I89). Con la llegada de la "devotio moderna» a España, según frase de Ortega, «la religión se hizo devoción». Como es natural, la Pasión de Cristo constituía una fuente segura de conmoción espiritual y afectos. Torres Naharro exclama en la Contemplación al Crucifixo: "Dame tu gratia, Señor, I por tal son, / y tan cicrta devoción / y tal parte en tus enojos; / que, pensando on tu passión / se me salga el coraçón / estilado por los ojos" (Gillet I. 204). C) sentido actual de devocion a un santo o lugar: "gran devoción tienen todas estas naciones extranjeras (a Santiago) (Viaje. I. 22). D) religiosidad en general: "... y si por semejante quisiere escrebir.la bondad, honestidad, devoción, caridad, castidad..." (La Lozana. Apolog. 247).-2. Devociones, plural: significa uoraciones» $o$, en un sentido más amplio, prácticas piadosas. Alicia pide a Celestina: "ruega en tus denociones por su salud a Dios" (I. Auto IV. I63); Pármeno dice: ".... porque nos entremos por la yglesia e ueremos si ouiesse acabado Celestina sus deuociones" (II. Auto IX. 24). En el Bando con que Cupido convoca al "Concilio de los galanes y cortesanas de Roma", dice a estas. ultimas: " $Y$ si vnestras devociones os hacen en Roma cstar, / en Bolonia ay estaciones, / indulgentias y perdones/quantos quisierdes ganar" (Gi- 
1let. I. 253). Bien se aprecia que el término "devociones», aunque de suyo tiene un significado objetivo —oraciones o prácticas-, acumula frecucntemente en el contexto, por la persona a que se refiere, una dimensión degradada, peyorativa. Lis el caso de los textos citados. Por el contrario, en el tratado II del Lazarillo el vocablo está usado en el sentido directo objetivo.-3. Devoto: A) con significación de "fervoroso" o "cargado de afecto", es aplicado a las oraciones: Celestina pide a Melibea "una oración que ella sabía, miny denota» (I. Auto VI. 2I9); el buldero "comiença una oración no menos larga que devota con la cual hizo llorar a toda la gente, como suelen hacer en los sermones de $\mathrm{Pa}$ ssión (V. I37). (Recuérdese el texto de Torres Naharro que acabo de citar). B) "actitud recogida» que traduce externamente el fervor: Lázaro admira en el ciego «... un rostro humilde y devoto que con muy buen continente ponía cuando rezaba, sin hazer gestos ni visajes con boca ni ojos" (II. 68). C) "piadoso", aplicado a personas: "que muchos vicjos denotos hauia - reconoce la Celestina- con quicn yo poco medraua" (II. Auto IX. 46); Susias reconicuda "yr muy callando, jor(que suclen leuantarse a esta hora... los denotos de templos, monesterios e yglesias" (II. XIV. I2I). D) es frecuente el uso en sentido irónico peyorativo: Sempronio recomienda a Calisto: "Por Dios, que huygas de ser traydo en lenguas, que al muy denoto llaman ypócrita" (II. Auto XI. 66). En esta línea parece inscribirse, como veremos, el calificativo que Lázaro otorga al buldero: "el devoto señor mío» (V. I36). Ocurre, sobre todo, en femenino y estrechamente vinculado a las cortesanas, a las cuales Francisco Delicado llama paródicamente "devoto femineo sexu» (Epíst. 257). Celestina habla de cómo los clérigos de todas dignidades, "cada qual, como lo recebía de aquellos diezmos de Dios, así lo venían luego a registrar para que comiesse yo é aquellas sus devotas") (II. Auto IX. 47); antecedente claro de la recomendación de Lázaro: "no nos maravillemos de un clérigo ni de un fraile, porque el uno hurta de los pobres y el otro de casa para sus devotas" (II. 65).-4) Devotamente: A) "fervorosamente», con intensidad de afecto: el buldero encomienda a los fieles "a que muy devotamente suplicassen» (V. I36); B) "recogimiento exterion》, que traduce el fervor interno: "muy devotamente le vi oir missa y los otros oficios divinos", dice Lázaro del escudero (III. I02).

Confirmado el carácter común e inmanente de la oración de Lázaro, tratemos ahora de apresar en el tratado $\mathrm{V}$, apoyándonos en estos datos semánticos, el significado propio de los vocablos pertenecientes a la familia léxica "devoción», así como su alcance dentro de la estructura general de la novela. Lixiste, a mi entender, un paralelismo de estructura léxica entre los engaños del ciego rezador y el que el buldero lleva a 
cabo. Lázaro habla allí de uoficio» (I. 68) y aquí de unegocio" (V. I3I); alaba en aquél su compostura de rostro devoto, que él mismo imita cuando tiene que pedir limosna —con baxa y enferma voz y inclinadas mis manos en los schos puesto Dios ante mis ojos y la lengua en su nombre" (III. II2)-, cn actitud muy semejante a la del buldero, quien use hincó de rodillas en el púlpito, y puestas las manos y mirando al cielo, dixo... (V. I34). La atención que en sus descripciones presta Lázaro al aspecto externo $y$, en concreto, a las manos y a los ojos-dos veces aún volverá a pintar al buldero ucon las manos y los ojos puestos en el cielo" (V. I55), "puestas las manos al cielo y los ojos que casi nada se le parecía sino un poco de blanco" (V. I37) - no parece casual ni desprovista de intencionalidad. Hay, viene a decir, un aspecto de devoción engañoso. El del ciego rezador, cuyo rostro uhumilde $y$ devoto" y grave voz (I. 68) aseguran un éxito, también probado por Lázaro. El del buldero - (devoto señor mion- que engaña a las gentes con la apariencia de sufrida humildad y divina contemplación. Igual el del escudero, al que Lázaro juzga persona de bien por su apariencia de honor, porque ha atribuido a la Providencia el que el muchacho topara con él-asegufle, dando gracias a Dios por lo que le oin (III. I02) - y porque «muy devotamente le vi oir missai) (III.' I02), y el cual, más tarde, se mostrará capaz de toda ruindad, con tal de salvar su porte externo (III. I35). La ligazón estructural, en esta veta temática, entre el hidalgo y el ibuldero aparece clara en los respectivos soliloquios de consideración generalizadora: a) "¿A quién no engañará - dice a propósito del tercer amo- aquella disposición?... ¡Oh Señor, y cuántos de aquestos debeis vos tener por el mundo derramados...l» (III. IIO); b) "Cuántas de estas deben de hacer estos burladores entre la inocente gente!n, exclama al final de la farsa de las bulas (V. I38). Todos tres -ciego, escudero y buldero- coinciden en poseer una habilidad o astucia para el engaño, que Lázaro adnira como eficaz instrumento en orden a abrirse paso en la vida. Varias veces califica al ciego de astuto (I. 68, 7 I y 74), y le alaba como sagaz (I. 68), sagacísimo (I. 75), "un águila en su oficio» (I. 68), de gran entendimiento (I. 74), ingenioso (I. 75), prudente (ibid.). Del escudero afirma que "quien no le conociera, pensara ser muy cercano pariente al conde de Arcos" (III. IOg), y, a renglón seguido, plantea la pregunta trańscrita: " $c^{a}$ quién no engañará aquella buena disposición y razonable capa y sayo?n; el propio hidalgo, por su parte, se confiesa presto a formar con éxito en el gremio de los astutos (III. 124). Por lo que se refiere al buldero, Lázaro le exalta entre todos los echacuervos como "el más desenvuelto y desvergonçado $y$ el mayor echador de ellas (bulas)... porque tenfa y buscaba modos y 
maneras y muy sotiles invenciones" (V. I3I); y cuenta uno de sus "mil mañosos artificios», "muy sutil», precisamente para probar "bien la suficiencia" (V. I32) del "industrioso y inventivo de mi amos (V. I38). He de aclarar, de paso, la inexactitud de la apreciación de don Américo, scgún el cual el buldero utiliza "la sacra ocasión de la misa»para sus artimañas. Según el texto, el pueblo es convocado a la misa $\mathrm{y}$, como acción distinta, al sermón-despedida de la bula (V. I33). El recurso, en suma, a una explicación de tipo coyuntural -iluminismo - erasmismo adversus religiosidad tradicional-, además de no encontrar un apoyo positivo, se queda corta. Lázaro no era un espiritu nuevo. $\mathrm{Y}$ al autor de la novela, adscrito por Bataillon a la ugran familia de los espíritus libres»" ${ }^{1}$, no le interesan las anécdotas en si mismas -picardía de los ciegos mendigos, fatuidad de los hidalgos arruinados, intolerables abusos en la mercancía de las bulas - sino en cuanto, engarzadas, estructuradas en convergencia léxica, contribuyen a esclarecer el "caso" de su criatura, clave de la novela. Así pues, aunque con distinto planteamicnto de motivación y desarrollo, los tres episodios responden a una filosofía común: la del engaño a los ojos. Il inocente Lazarillo del comienzo del rclato se convierte en el desengañado Lázaro del Tratado VII, porque la vida le ha enseñado que los valores más altos - religión, honor- son muchas veces pura apariencia.

\section{Inquisición sobre la ortodoxia}

Hablamos del Dios de Lázaro. Pero, ¿es El, realmente, el Dios de los cristianos? Américo Castro anota la ausencia, en un lenguaje tan popular como el del Lazarillo, de los nombres de Jesús, La Trinidad y María, así como la escasez del santoral. Esto significaría, según él, "dejar en hueco lo que en el cristianismo no es común con la religión mosaica». He rastreado cuidadosamente La Celestina, La Lozana y la Propalladia; descarto en esta ocasión el Viaje, porque, al describir la vida monástica y cristiana en general del área mediterránea, forzosamente ha de utilizar a cada paso dichos nombres. Pues bien, el nombre de Jesús sólo aparece en La Celestina en forma de exclamación, simple, duplicada o triplicada, y es usado: una vez por la vieja (I. Auto I. 98) y por Elicia (II. Auto VIII. 3I), dos por Melibea (I. Auto IV. I78 y s.) $\mathrm{y}$ tres por Areúsa (I. Auto VII. 248, 257 y II. AutoXV. I34); no aparece en La Lozana y se da sólo seis veces en las ocho comedias de

1 Novedad..., p. I8. 
Torres Naharro: cinco veces en la Jornada IV de la Calamita. (Gillet, II. $428,429.446$ y 454 ) y una en la Jornada V de la Aquilana (Gillet, II. 557). Encontramos, además, en la Jornada I de la Seraphina "¡Per lo ventre de Jhesul" (Gillet, II. I4), en la V de la Trophea, "iHo dot' al Verbo devino!" (Gillet, II. I32), en la Tinellaria - Jornada III- "iVoto a Dios, si fuesse Christol» (Gillet, II. 226) y en la V de la Ymenea, "Plega al devino Messías" (Gillet, II. 3I9). No se da referencia alguna en la Soldadesca ni en la Jacinta. Como prácticamente inexistente puede juzgarse el vocablo "Trinidad", que sólo se encuentra una vez en la Jornada V de la Seraphina; "Válame la Trinidad!" (Gillet II. 7I). El nombre de María aparece dos veces, también en forma de exclamación, en La Celestina, en boca de Pármeno (I. Auto VI. 209) y de Calisto (II. Auto XIX. I84); no se da en La Lozana y es, en cambio, relativamente usual, pero siempre en forma exclamatoria lexicalizada, en Torres Naharro; "Virgen Maria» aparece ocho veces en la Seraphina (Jornadas I. 5 y I6; II. 25, 28, 3I y 32; IV. 64; V. 73) y una en la Tincllaria (Jornada III. 225), Ymonca (Jornada I. 285), Calamita (Jornada IV. 428) y Aquilana (Jornada I. 478); "la Virgen Nuestra Señora", una vez en la Calamita (Jornada IV. 430) No se da referencia en la Jacinta ni en la Trophea. Hay que añadir dos alusiones a "Santa María de Agosto" como indicación temporal: Tristán, en el Auto XIV de La Celestina (I. I2I) y ell el Introyto de la Soldadesca (Gillet, II. I42) ${ }^{2}$. Por lo que hace, finalmente, al santoral, es absolutamente reducido en La Celcstina; en ella, como en el Lazarillo, encontramos dos veces "Sant Juau»: "sea lo passado questión de Sant Juan", dice Sempronio (II. Auto VIII. I6), frase cuyo núcleo semántico es el nismo del «a tercero día hacíamos Sant Juan" (I. 74) ${ }^{2}$; la vieja Celestina invoca, sobre Areúsa, la bendición del useñor Sant Miguel, angel» (I. Auto VII. 249). En Torres Naharro no hay un criterio uniforme de uso: en tanto que en la Trophea se nombra a San Martín (Gillet, II. I22), San Pedro (IV. I23), San Pelayo (IV. I27) y Sant Llorente (V. I33), en el resto de las comedias aparecen, sólo esporádicamente, Santo Thomás apóstol (Yincnca. Jornada I. 283), Sant Agustín (Jacinta. Jornada IV. 352), Sant Rodrigo (Calamita. Introyto. 369) y Sant Juan y Santa Clara (Aquilana. Introyto. 460 y Jornada II. 487). Los datos obtenidos

1 Cf. GILIEr, III, 387, núm. 30, donde se encuentra abunciante documentación folklórica sobre este topos.

- Ademís de ser una fiesta riquísima en tradición folklórica, el día de San Juan cra cl scĩalaclo para payar las rentas y cambiar de amo o sirviente (Cf. Gil.LET, III, 387, wím. 3I). 
en este cotejo privan de fuerza argumental la advertencia de Castro. En efecto, no se puede afirmar documentalmente que en todas y cada una de las obras literarias del XvI abunde la onomástica religiosa. Desde luego, el vocablo que con más frecuencia se utiliza es "Dios»; "Jesús", "María" y los santos aparecen - siempre, nótese bien, lexicalizados en exclamaciones - de forma esporádica y circunscrita a la expresividad coloquial concreta de algún protagonista.

\section{A) Lázaro ante la Eucaristia}

He aquí un tema en el que, desde diversos ángulos interpretativos, a veces contradictorios entre sí, los críticos quieren ver reflejada la peculiar religiosidad de Lázaro y del Lazarillo en general. Suelen aducirse en este punto tres pruebas de falta de fe (Castro, Gilman) o de una fe heterodoxa (M. J. Asensio, Márquez Villanueva, I'ipcr, entre otros): el desinterés de Íázaro por la Misa, la parodia eucarística del arcaz y el juramento sobre la hostia consagrada. Contemplemos cada una por separado. I. La primera de ellas se condensa en la observación, hecha en primer lugar por Castro y que muchos comparten, de que cuando Lazarillo topa con el escudero y le acompaña a la iglesia, dice "le ví oir Missa", pero no dice que la oyera él: luego no cree en la Eucarístía. Con todos los respetos, entiendo que tal interpretación constituye una clara extrapolación de contexto. El dato umuy devotamente le ví oir missa" se inscribe en el proceso descriptivo de observación y juicios que Lázaro va haciendo sobre el escudero. Veamos. El diálogo de contrato ha sido muy breve. Algo le dice interiormente al muchacho que, por fin, ha encontrado la suerte. Se lo hace sospechar de entrada, como sugería poco más arriba, un doble motivo: religioso y de honor. Para Lázaro representa mucho el que el escudero atribuya su encuentro al favor de la Providencia divina. El dato converge en significación hacia el núcleo estructural de la novela, puesto que una vez más Dios protege a Lázato, poniéndose - parece- (ad usun Lazari». La otra causa, simultánea, de la repentina entrega del muchacho al escudero es que, según propias palabras de aquél, "me parecia, segin sı hábito y continente, ser el que yo había menester» (III. I02): fuerza del aspecto de honor. De inmediato, el hidalgo ha ordenado - nueva muestra de autoridad que la honra confiere-: "Pues vente tras mi»; y echa a andar con paso decidido. Lázaro dice: «seguíle...», «llevóme tras sí gran parte de la ciudad». En este punto comienza cl genial proceso de observación y juicio a que me refiero. A) "Era de mañana», acota Lázaro; pasan 
las plazas del mercado y el muchacho espera que de un momento a otro su nuevo dueño se detenga y señale las mercancías de su preferencia, pero el hidalgo sigue a su paso; B) Lázaro piensa: "por ventura no lo ve aquí a su contento" (III. I02). A) "Entonces se entró en la iglesia mayor y yo tras él, y muy devotamente le ví oir missa y los otros oficios divinos...n; B) No nos dice expresamente lo que pensó, más evidentemente se ratifica en la convicción de haber topado con un hombre importante, con su hombre. El proceso continúa estructurado mediante la ilación temporal: era de mañana, entonces. A) "Entonces salimos de la iglesia. A buen paso tendido...n; B) «bien consideré que debía ser hombre... que se proveía en junto, y que ya la comida estaría a punto...n (III. IO" y s.). $\mathrm{Y}$ así... hasta el desengaño. Ein todo el proceso, al autor no le interesa poner de relieve en la acción del Lazarillo más que la atenta observación, sin pestañeo, el atisbo del menor detalle que pueda confirmar venturosamente su esperanza. Parece que podría añadirse aquí a nucstro favor la expresa declaración de Lázaro de que el ayudar a misa fue una de las umil cosas bucnas» que le aprendió cl cicgo (II. 83). El calificativo "buenas", sin embargo, conlleva en este caso una clara especificación semántica contextual de pragmatismo: cosas buenas - cosas útiles. En todo caso, uingún gesto de presencia de Lázaro en el culto -en el tratado VI lo vemos entrando en la iglesia mayor (I39)induce a pensar en falta de fe teórica o práctica.

2. No es difícil - y mucho menos debia serlo en el siglo xvIdescubrir en el episodio del arcaz una relación paródica con la eucaristía: hay un arcaz-sagrario, donde están reservados los bodigos en los que Lázaro ve la "cara de Dios" y a los que adora sin osar recibir; el clérigo guarda celosamente la llave de este tabernáculo, pero un ángel enviado por Dios, el calderero, abre a Lázaro las puertas del paraíso. A. C. Piper ${ }^{1}$ va aún más lejos y estruja al máximo el contenido simbólico potencial de estos y otros elementos que, a su juicio, destilan una virulenta sátira eclesiástica. En el episodio, explica, contienden la Iglesia oficial, representada por el clérigo, y el pueblo de los pobres que busca a Dios. por los caminos marginales del iluminismo. Lázaro, el pobre, está "excomulgadon de la participación eucarística y el clérigo, falto de caridad, le priva del pan de vida, profanando las palabras del Señor en la Ultima. Cena: "Toma, come, triunfa, que para tí es el mundo". Dios envía su ángel a socorrerle y Lázaro entra en el paraíso. Todo parece resuelto. Pero la Iglesia oficial es fuerte y ve en ello un pecado de herejía: Lázaro.

1 The Brcadly Paradise of Lazarillo de Tormesn. Hispania, I961, XLIV. pp. $269-271$. 
será, así, expulsado del paraíso, precisamente traicionado por el silbo de la llave-serpiente genesíaca. Concluye Piper: "Once the priest has. ferreted out heretic he banishes him from his house. Satisfied that the arcaz is now safe and that the "key to salvation" is no langer in unauthorized hands, the priest crosses himself and shuts the door. The "altar» is now secure, and the door has beem firmly. Closed to further heretical movements» (p. 27I). Este maximalismo interpretativo resulta, a todas luces, infundado. No parece, en efecto, coherente el que Dios se alíe primero con Lázaro y enseguida con sus enemigos. Tampoco. son admisibles algunas de las referencias simbólicas establecidas. Fue Cejador el primero en relacionar las palabras del clérigo de Maqueda con las de Cristo en el Cenáculo (Mat. 26, 26 y s.) ${ }^{1}$. Pero ni la semejanza textual parece estrecha ni se ajusta al contexto inmediato de la novela, ya que la parodia eucarística comienza más adelante. En ambos sentidos, textual y contextual, las palabras del cruel sacerdote evocan más de cerca aquéllas del rico avaro: "HIombre, tienes bienes acunulados para muchos años: túmbate, come, bebe y date buena vida» (Iuc. I2, I9). Todo se relativiza más aún al comprobar que se trata de un topos, señalado ya por I:. Rico 2: en La Lozana, Leonor, refiriéndose a Aldonza, dice: "Bien parece que come, y bebe y triumpha" (XIVIII. I92); poco antes había afirmado la protagonista: "como a mis espesas y sábeme bien, y no tengo envidia al Papa, y gánolo, y osténtolon (XIIV. I8I). Tampoco debe especularse mucho con las reiteradas anteposiciones de "como dicen», "ansí dicen" al sintagma "cara de Dios»; se trata de engarzar en la parodia una costumbre popular documentada por $\mathrm{Co}$ rreas y que debía de estar muy extendida ya que Pedro de Urdemalas la observa también entre los turcos (Viaje. II. IIg). Lázaro Carreter, por último, ha indicado el carácter folklórico del paso de la serpiente ${ }^{3}$.

A pesar de estas restricciones interpretativas, ¿wo nos encontramos aquí con una sacrílega profanación, reveladora de increencia o herejía? Digamos, ante todo, que según documenta E. Asensio ${ }^{4}$, el pueblo del XVI, muy habituado a la alegorización de textos sacros, adivinaba enseguida la relación de un hecho o situación con Cristo o la liturgia. "Por mucho que nos choque, afirma, raros eran los que se escandalizaban de que el poeta calcase la Pasión de Cristo sobre el texto que celebraba.

1 İdic. del Lazarillo. Clásicos Castellanos, p. Ir6.

2 Cf. F. RICo, Introducción, p. 33, nota 36.

3 Construccion y sentido, p. 90.

- La peculiaridad..., p. 342. 
la pasión, azotes y afrentas de un ladrón como Escarramán». Recordemos que Quevedo en el Buscón teje la descripción de las novatadas de Alcalá sobre cl caũamazo de la narración evangélica de las afrentas de Cristo ${ }^{1}$. Ia glosa o doble juego paródicos con textos bíblicos o litúrgicos son abundantísimos en las obras que vengo cotejando. Hoy nos deja atónitos, por ejemplo, aquel diálogo de Sempronio y Calisto, parodia del Génesis I9, 4. Dice Semproniou... no pensaua que haufa peor inuención de pecado que en Sodoma». Calisto, extrañado: "Cómo?». Sempronio: «Porque aquéllos procuraron abominable uso con los ángeles no conocidos é tú con el que confiessas ser Dios» (I. Auto I. 44). Pues bien, el único efecto que tan blasfemo despropósito produce en Calisto y en el auditorio es la risa: "iMaldito seasl. que fecho me has reyr, lo que no pensé ogañon. La Lozana utiliza para sus chistes fálicos el cirio pascual (XVII. 88) o la usede vacante» (XXVII. I27). Pero es, quizás, Torres Naharro, a quien nadic acusó de heterodoxia, quien nos brinda las parodias más populares y atrevidas. Liscogeré solamente algumas de las cucarísticas. In la Jornada IV de la Tinellaria, Iiscalco, Canavario y Barrabás empinan el codo lasta la borrachera con esta parodia del "Domine non sum dignus" y del "Quid retribuam", oraciones que el sacerdote recitaba antes de comulgar el cáliz:

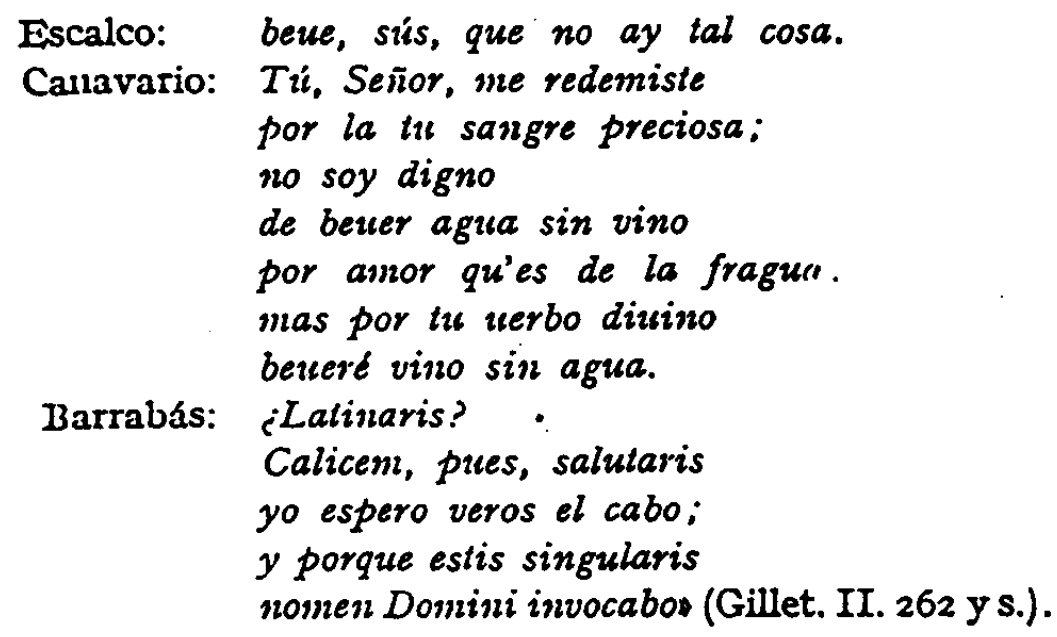

En la misma línea se sitúan las parodias del Introyto de la Ymenea (Gillet, II. 273) y del Diálogo del Nascimento (Gillet, I. 267). Así, dentro de tal contexto general, la parodia del tratado II del Lazarillo, tejida de elementos folklóricos, es sólo una más y bieu discreta por cierto.

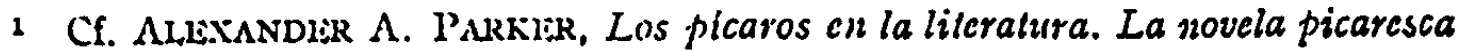
.cn España y Europa (I599 - 1753). Madrid, Gredos, 197r, p. I I9 y s. 
3. El juramento de Lázaro al final de la novela ha de ser, igualmente, valorado en su precisa significación estructural y de acuerdo con los usos del tiempo. Cuando, tras mil lacerias, se considera integrado cil la socicdad y amparado por un micmbro del cstablishncnt, he aquí que, de repente, un nubarrón ennegrece su horizonte. Si Lázaro da oidos a las habladurías sobre su mujer, todo se derrumbará y él habrá de volver a los caminos de la laceria. Ha bastado una sola palabra para que su mujer echara tales improperios, "que quisiera ser muerto antes que se me hubiese soltado..." (VII. I44). De ahí la decisión de no decir ni admitir nada que pueda poner en peligro la estabilidad. Cuando alguien, con mejor o peor intención, aborde el tema, Lázaro le atajará con un párrafo hecho, cuyo esquema conviene analizar. Ia prohibición se desarrolla con intensidad creciente en tres tiempos temáticos, que tienen por denominador común el engaño a los ojos: A) afirina que "mi mujer es la cosa del mundo que yo más quiero, y la amo más que a mi, y me hace Dios con ella mil mercedes", cuando, en realidad $-\mathrm{y}$ el lector to sabe-, sc ha casado con clla por el interés; B) se declaril presto a poner a Dios por testigo de su absoluta convicción sobre la honradez de su mujer, cuando más de tres veces le han certificado que otras tantas había parido de soltera: de nuevo Lázaro se revela aquí como un cofrade de quienes utilizan la máscara religiosa para encubrir una turbia realidad; C) el muchacho que siempre rehuyó la violencia, a favor de la astucia (I. 67), y despreció los litigios de honor (III. I20 y s.), desafía valentón a quien ose empañar la menos que dudosa honra de su mujer: "quien otra cosa me dixese, yo me mataré con él». Tres soberanas mentiras, en fin, al servicio de su «honorable» situación. El pecado - digámoslo ya- consiste en poner a Dios por testigo de ellas, y nada añade en gravedad el que sea citado en forma de la hostia consagrada. Esto constituía una fórmula usual más. En el Viaje, Juan de Voto a Dios, para defender la elegancia de la lengina castellana, dice: "Yo juraré en el ara consagrada" (I. 27). Y otro dato, de diverso signo, más revelador. Cuando el Inquisidor General Valdés Salas se resiste a ayudar a la Hacienda Real en la cuantía económica que el Emperador le exige, Carlos V envía al contador Hernando de Ochoa para negociar. En el forcejeo de la entrevista - escribe Ochoa- el arzobispo "díjome delante de un sacramento que los diablos le llevasen, si nunca tuvo cien mil ducados juntos» ${ }^{1}$. ¿No alude, con claridad, a un juramento eucarístico? Hay que descartar, en conclusión, los pretendidos indicios de una incredulidad o de fe heterodoxa de Lázaro en la Eucaristía.

1 Josf: I,UIS G. Novarif, El Inquisidor General Fernando de Valdés. Su vida y obra. Uuiversidad de Ovicdo, 1968, p. 290, nota Io. 


\section{B) El anticlericalismo del Lazarillo}

María Rosa Lida ha señalado con gran lucidez cómo la sátira anticlerical de la Celestina, que destaca "no sólo por su abundancia y rigor sino por ser este el úuico orden social criticadon e implicar a la Iglesia como institución humana, se diferencia de la del Lazarillo por cuanto en esta novela se trata de sentimientos religiosos individualizados ${ }^{1}$. Pasemos revista a los diversos tipos de clérigos protagonizados y tratemos de precisar la función de cada uno en la estructura orgánica de la obra.

I. El clérigo de Maqueda. Un cura rural en el último escalón del estamento eclesiástico. No es necesario insistir en el bajo nivel cultural y moral del clero en el xvI. "Los clérigos y curas -informa por aquellos años el canónigo ovetense Andrés de Prada a San Francisco de Borja ${ }^{2}$ de ordinario son idiotas porque los beneficios son muy temues». A pesar de las reconocidas riquezas de las ticrras toledanas ${ }^{3}$, no faltaban alli iletrados "le los reverendos" (V. I32), a quienes se pucde sobornar con algunas cosillas no tampoco de mucho valor ni substancia: una lechuga murciana, ...un par de limas o naranjas, un melocotón (V. I3r). El de Maqueda era un avaro de la peor especie, avaro en la sordidez. Ios calificativos morales que Lázaro le dedica son terribles: (lacerado" $(86,89)$, mentiroso (86), "mezquino" (87), "cuitado, ruin y lacerado" (88), "misero" (89), "bruxo" (97), "cruel» (98), "desventurado y misero» (I04), "malaventurado mezquino" (II5). ¿Bastará el hambre para justificar tal letania? Entiendo que no. Ia espolea, a mi juicio, la doble circunstancia agravante de su condición y de que, siendo también él pobre, se condene a la avaricia. I a sufrida convivencia con él hace caer de los ojos de Lazarillo una de las muchas vendas de convenciones: parecía por su hábito uno de los buenos a los que su madre le había aconsejado arrimarse; pretendía, incluso, camuflar su avaricia bajo el manto de la virtud de la templanza (II.: 86). Todo era engaño a los ojos. Con frecuencia ha querido verse en él un símbolo generalizado del clero al que un autor erasmista acusaría de avaricia con la reticencia de Lázaro: "No sé si de su cosecha era, o lo había anexado con el hábito de clerecía"

- MLARfA ROSA IIWA, La originalidad artistica de La Celestina. Buenos Aires Eudeba, 3. edición, x97o, pp. 363-369.

Cf. G. NovaríN, Op. cit., p. 78.

- ¿Por qué pieusa Vuestra Alteza que hizo Dios cerca de las Asturias y montaũas a Campos y al reino de Toledo, sino para que estas tierras mantuviesen los polres de las otrasn? Fray Domingo DE Soto, Deliberación en la causa de los pobres. MIadrid, 1965, p. 38 (Cf. F. MARQUEZ, Op. cit., p. 12I). 
(II. 83). Esta frase, sin embargo, evoca un topos. La Lozana se lamenta de las dificultades del oficio en la Roma de entonces: «... nunca tan gran estrechura se vido en Cataluña ni en Florencia como agora hay en Roma; y si mirais en ello, entonces traían unas mangas bobas, y agora todos las tracn a la perladcsca (XI,IV. I82). La "manga cstrecha", que hoy se refiere a escrupulosidad de conciencia, significaba entonces lo que en la actualidad se expresa por "puño cerrado». En cualquier caso, el chiste malicioso basado en la relación avaricia-manga estrecha del hábito de los clérigos pertenecía al acervo común. En favor de su tesis de interpretación erasmista, Márquez Villanueva acusa al pobre cura de Maqueda de incredulidad, de ser un "ateo práctico». Se basa para ello en dos pruebas concretas: el recurso a la vieja ensalmadora y la actitud que adopta durante la celebración de la misa. Pedro Ciruelo habla en su Reprobación de las supersticiones y hechicerias de "dos maneras principales de ensalmos. Unos dellos son de solas palabras: que ninguna otra cosa ponen al paciente: otros juntamente con las palabras ponen algunas otras cosas sobre la herida o llaga» ${ }^{1}$. Iin realidad, el procedimicnto puro -que Juan de Valdés, entre otros, incluía en las prácticas de hechicería - se daba muy pocas veces. Io frecuente era el tipo de mujer que encontramos bien definido en el autorretrato de La Lozana: "Yo sé ensalmar y encomendar y santiguar... Sé quitar ahitos, sé para lombrices, sé encantar la terciana, sé remedio para la cuartana y para el mal de madre... Sé hacer que no duelan los riñones y sanar los renes... sé ensolver los sueños, sé conocer en la frente la fisonomía, y la quiromancía en las manos, y prenosticar» (XIII. I76). Idéntico esquema utiliza Pagano en la Jornada V de la Jacinta (Gillet, II. 360 y s.). Ia ensalmadora del Lazarillo llega con los vecinos a vendarle la cabeza y ponerle mejunges. ¿Falta de fe del cura? El no pertenece, desde luego, al grupo denunciado por Fray Martín de Casteñega de "clérigos necesitados y codiciosos que por officio toman de ser conjuradores, hechiceros, nigrománticos y adevinos, por se mantener y tener de comer abundosamente...1 ${ }^{2}$. Pienso, además, en los breviarios, misales y manuales de la época, publicados con "imprimatur» eclesiástico y cargados, sin embargo, de oraciones y liturgias impetratorias no menos supersticiosas que las prácticas habituales de los ensalmos ${ }^{3}$. Si la presencia de la

\footnotetext{
1 Salamanca, I538, fol. XXXJ ro. Cf. Gillet, III, 626-628.

2 Tratado muy sotil y bien fundado de las supersticiones y hechicerias. Logroño, I529, cap. I. Sin numeración.

3 Il Misal Ovetense, mandado publicar por el Inquisidor Valdés $y$, por consiguiente, muy depurado, atribuye especial eficacia a la misa "pro vitanda roortalitaten, si se oye de rodillas, durante cinco dias consecutivos y con cirios en la manon. Cf. Novarín, Op. cit., p. 93.
} 
vieja ensalmadora en casa del cura demuestra falta de fe, hay que concluir que en la España medieval, renacentista, barroca y hasta en la Isspañz del xvirI -recuérdese a Feijóo- no creía casi nadie. Pero la incredulidad es algo muy distinto de una fe con adherencias supersticiosas. $Y$ estas fucron denunciadas no sólo ni en primer lugar por Erasmo y sus seguidores: bastan los dos libros de época citados, para confirmarlo. Más expresiva de ausencia de fe parece, a primera vista, la escena en que el cura de Maqueda, durante el ofertorio de la misa, vigila las monedas que caen en la concha de las limosnas: «bailábanle los ojos en el caxco como si fueran de açogue (II. 85). Mas también en este caso se trata de un conocido topos. La vieja Celestina cuenta cómo entrando ella por la iglesia, "vía derrocar bonetes en mi honor... De media legua que me viessen, dexaban las Horas... Uno a uno, dos a dos, venían adonde yo estaua, a ver si mandaua algo, a preguntarme cada. uno por la suya. Que hombre hauía que estando diziendo missa, en uiénclome cutrar, se turbaua, que no fazía ni dezía cosa a derechas甘 (II. Auto IX. 46). No es difícil determinar en este parlamento una estructura gradativa hiperbólica, que culnina en la sacrilega deuuncia y cuyo esquema toma prestado el autor del Lazarillo para resaltar al máximo la avaricia. De nuevo es preciso, en consecuencia, aplicar aquí el principio metodológico de que, tratándose de un recurso común, el pasaje carece de intencionalidad específica.

2. El fraile de la Merced. Los rasgos que le definen son perfectamente tópicos. Lázaro Carreter, además de sugerir el recuerdo de Apuleyo, aduce textos de Sánchez de Badajoz, Horozco y fray Antonio de Guevara ${ }^{1}$, ninguno de ellos, por cierto, sospechoso de erasmismo, y F. Rico completa la lista con Gil Vicente, que tampoco conoció a Errasmo ${ }^{2}$. Bataillon recuerda, oportunamente, que la crítica contra clérigos y frailes disolutos era especialmente dura entre los monjes reformados y en el ambiente de los clérigos instruídos ${ }^{3}$. El teatro de Torres Naharro, por ejemplo, rebosa acusaciones durísimas de lujuria y holgazanería (Seraphina. Jornada I. I5), reticencias - "tu mujer sē lleve un frailen, exclama Caxcolucio en la Jornada II de la Trophea (Gillet, II. I04)-, hasta culninar en el apóstrofe de Atambor: "¿O pensais qu'el parayso / | fue hecho para los flayres?" (Soldadesca. Jornada II. I60). Escribiendo esto en Roma y publicándolo con todas las bendiciones eclesiásticas, el clérigo pacense iba nucho más allá que Erasmo, a quien no había

\footnotetext{
Construcción y' sentido, p. I 10 y s.

AI. BaTaulon, Erasmo y España, p. 6I3.

3 Novedad..., p. 20:
} 
leído ${ }^{1}$. ¿Nada nuevo, entonces, en el tratado IV del Lazarillo?. Sí. La tradicionalidad generalizada se individualiza en el molde de un mercedario. $Y$ es esto - -1 cuño de originalidad - lo que, paradójicamente, despoja al tratado de cualquier sospecha de heterodoxia. En la primera mitad del xvr la animadversión contra los mercedarios era general. Ein el Viajc se pronuncia contra ellos una acusación fortísima. Quejándose Pedro de Urdemalas del olvido en que la Patria tiene a los españoles cautivos, pregunta Juan de Voto a Dios: «Pues de las limosnas d'España que hay para redempción de cautivos, ¿no podrán hacer conque rescatar en buen precio hartos?». A lo que Pedro responde, airado: "¿Qué redempción? ¿Qué cautivos? ¿Qué limosnas? Córtenme la cabeza si nunca en Turquía entró real de limosna» (II. I5). La Lozana habla de «otra abacera, que de su tierra acá no vino mayor rabanera, villana, tragasantos, que dice que viene aquí por una bulda para una ermita, y traye consigo un hermano fraire de la Merced, que tiene una nariz como asa de cántaro y el pie como remo de galera" (VII. 50). Me parece que se pone de relieve el cargo de negociadores que en el Lazarillo se fustiga, agravado en este caso con la alusión a la nariz judía. No era sólo malevolencia popular. En I542 el Rvdmo. Marroquín, obispo de Guatemala, se queja del contraste que en el Nuevo Mundo presentan los mercedarios con otras órdenes misioneras y llega a decir que más valdría haberlos expulsado de América ${ }^{2}$.

3. En cuanto al buldero, si un cotejo textual con Il Novellino de Masuccio arroja un buen saldo de variantes, resulta innegable la semejanza formal existente en la descripción de la fingida posesión diabólica ${ }^{3}$. Teniendo en cuenta que el núcleo del relato aparece, también, en un flamenco Liber vagatorum, hay que aceptar, como mínimo, el origen tópico folklórico de la anécdota. ¿Qué traduce, en ese caso, la especificación erasmista? Márquez Villanueva la aprecia en una cuidadosa distinción entre el ataque a las bulas y el reconocimiento de las indulgencias. Me parece una sutileza innecesaria. Torres Naharro denunciaba en Roma a comienzos de siglo el comercio de indulgencias. Escribe asi en el II de los "Capítulos diversos»:

1 M. BatarliLon; Erasmo y España, p. 6r3.

2 C. M. BATaurion, El sentido de Lazarillo de Tormes. Paris, Libr. des Edit., espagnoles, I954, p. I3, nota I4.

3 Cf. F. Rico, Introducción, p. XXXIX y s. 


\author{
Hazen de Dios tal extima \\ que les passan por encima \\ a mil cuentos de indulgencias. \\ Quien the entiende \\ verd qu'es Roma, por ende, \\ si $n$ fucsse puro necio, \\ una costumbre de allende, \\ un mercado do se vende \\ lo que nunca tuvo precio (Gillet, I. I64).
}

El interpolador de Alcalá demuestra haber entendido bien la dirección de esta crítica, cuando describe el furor con que el pueblo tomaba a más tomar las bulas uaun para los niños de la cuna y para todos sus defuntos, contando desde los hijos hasta el menor criado que tenían" 1 . Pero las bulas eran sólo un capítulo -quizás, sí el más flagrante de la España del XVI- de una depauperada vivencia religiosa. $Y$ el tratado $V$ resulta así uno sólo de los mil cuentos de echacuervos que, según Antonio de Fucnunyor (I595), circulaban por Ispaña a propósito de echacuervos, gemelus de los unill cuentos de invenciones de fraires" que, segúm. Juan de Voto a Dios corrían también por Europa. "¿Visteis diunca -pregunta Mátalascallando- al diablo pintado con hábitos de monje? "Hartas vecesn, responde aquél. Pedro de Urdemalas relata entonces el caso de "algunos bellacos españoles», seis, en concreto, que andaban confesando y descubrían unos a otros los pecados de sus penitentes a fin de que, abordándolos después, estos creyeran que los confesores gozaban del don de discreción de espiritus. Naturalmente, todo terminaba en un pingüe esquilmo de las bolsas. El esquema del truco varía, pero la esencia de la facecia es la misma que en el tratado $V$ : asociación de hombres de iglesia para engañar a los fieles con fingidos dones espirituales. Queda claro, de este modo, que el episodio del Lazarillo pertenece a una precisa corriente faceciosa y que lo único que hace el anónimo autor es circunstanciar, al lispánico modo y según patrones muy ceñidos a modelos preexistentes, un material folklórico.

4. Tras el agudísimo buldero, pasa fugazmente por escena un capellán de la iglesia mayor de Toledo, dejando el rastro de la usura en el saneadísimo negocio de concesión de aguas, que le teporta treinta maravedís diarios y que, al cabo de cuatro años de trabajo y ahorro, permite a Lázaro mercarse «opa vieja" y uuna espada vieja de las primeras de Cuéllarn (VI. I39 y s.).

Viene discutiéndose nucho sobre la necesidad e hipotética función estructural de los tratados IV-VI. Frente a Rumeau, que habla de rup-

1 Edic. de Jost Caso, Apéudice, p. 149. 
tura de continuidad ${ }^{1}$ y Willis, para quien Lázaro está moralmente configurado al final de su aventura con el escudero ${ }^{2}$, Charles Minguet cree que los episodios contenidos en dichos tratados cumplen una triple función: a) orgánica, la de condicionar aún más la incredulidad de Lázaro; b) marginal, aportando indicios de tipos sociales y folklóricos interesantes; c) conceptual, que no es sólo la que le atribuye los defensores del erasmismo del autor ${ }^{3}$. Todos estos aspectos se articulan, según el hispanista francés, sobre el doble eje de la burla y la espera confiada en un milagro liberador de la miseria. A mi modesto entender, aunque los tres tratados obedecen a una misma técnica narrativa - ensartado lineal de facecias 4 y coinciden en presentar un Lázaro espectador en vez de actor, no cabe homologar indistintamente sus funciones estructurales. Vistas la fácil autonomía con que Lázaro por primera vez se produce y la distancia sicológica con que narra el episodio, se impone afirmar que la semana vivida con el mercedario no le condiciona moralmente. In este sentido, el relato no aporta al núcleo de la novela, en convergencia, ningun contenido semántico nuevo. 'lampoco se puecle clecir por eso que sca absolutamente divergente, puesto que, al menos, contribuye al equilibrio de proporciones del conjunto y dentro de él cumple una función propedéutica indicativa: el Lazarillo abandonado por el escudero, viene a decir, ya no será en adelante abandonado por nadie; es dueño de sí mismo y será él quien elija y abandone. Me interesa, sin embargo, aclarar que, en esta dimensión semántica tangencial, el contenido específico del episodio no es pertinente. Quiero decir que al autor le interesa poner de relieve la iniciativa de Lázaro frente ua un amo»; la elección particular de «este» amo se resuelve en pura anécdota, deuda al tópico folklórico. Caso muy distinto es el tratado $V$, cuya función semántica expliqué al tratar el tema del engaño a los ojos.

1 A. Rumanu, Le Lazarillo de Tormes. Essai d'interpretation, essai d'attribution. Paris, 1964, Propugua para cstos capitulos la autoria intencional de un erasmista.

2 Segúu eso, los tratados IV-VI responden a la necesidad de cstablecer una transición entre el tratado III y el VII, a fin de justificar la ironia universal con que se cierra la novela. Se conseguiria, sobre todo, con el tratado V, en el que Ĺázaro contempla divertido el engaño, reducir a sus justos limites la simpatía del autor por el protagonista, hombre ya, moralmente hecho y derecho, y desembarazar, al tiempo, al propio Lázaro de la angustia que le acompaña en los tres primeros tratados.-R. S. WIILIS, Lazarillo and the Pardoner. The artistic necessity of the Fifth Tractadow. HR, 1959, V, pp. 267-279.

3 CinarIEs MINGUET, Recherches sur les structures narratives dans "Le Lazarillo de Tormesn. Paris. Centre de Recherches Hispaniques, I970, Pp. I I I-I2I.

- Cf. Idzaro Carritere, Construcción y sentido, p. 72 y ss. 
Lázaro es ahora espectador, pero integrado en la escena; de ah́ que la distancia psicológica respecto de lo narrado se acorte en favor de apreciaciones subjetivas. Hacia el mismo tema del engaño gravita la segunda parte del tratado VI. Tambiéı quedó insiuuado. Apenas logra ahorrar cuatro cuartos, 10 primero que Lázaro hace es vestirse umuy honradamente», para ocultar con un jubón de fustán vicjo, una capa raida y una espada orinada, la bajeza del oficio de aguador, propio de moriscos. Es un engaño que a nadie engaña. ¿Qué importa? A fin de cuentas, constituye el juego del siglo.

5. Poco resta por añadir a propósito del arcipreste de San Salvador. Aualizado su carácter tópico, quizás baste con dejar constancia de que, sunque él sea la causa inmediata del "caso" de Lázaro, no ha sido él sólo el primero ni el único responsable de su ruindad moral.

En conclusión de este ya largo capítulo sobre el anticlericalismo, quicro scñalar algo que me parece decisivo. $Y$ es cl hecho de que el autor del Lazarillo, en un momento en que la literatura satiriza al intcgro cucrpo cclesid́stico, desde el Papa al menor sacristán, pasando por obispos y canónigos, centre su atención exclussiva en los grados más bajos del estamento, presentando unos tipos elaborados a base de material folklórico. Esto obliga a desechar cualquier interpretación trascendente. Aparte de las acusaciones genéricas de La Celestina, pienso, por ejemplo, en los ataques directos de Torres Naharro al Papado: "La corte tiene fatiga / y el Papa se está a sus vicios", dice Precioso en la Jornada V de la Jacinta (Gillet II. 358). A cada paso alude a su vida de riqueza (VIII de las Epistolas familiares I. 203; Jornada IV de la Tinnelaria II. 240; Jornada IV de la Aquilana II. 547). Por no citar la Sátyra, suprimida. en la edic. de 1573: "..falsarios vereis robar beneficios, / ladrones a furia comprar los officios / y a costa de Dios andar a solacion (Gillet, I. I56 y ss.). Los reformadores católicos y los refornistas heterodoxos dirigian los dardos más acerados de su crítica contra la cabeza y los miembros rectores de la Iglesia. Nada de esto se encuentra en el Lazarillo. Sería ciego quien no viese en la novela el trasfondo de una situación histórica que condiciona la fantasía individual y la fisonomía estilística ${ }^{1}$. Hay, sin duda, sátira anticlerical. Pero Bataillón definió certeramente su naturaleza y filiación: anticlericalismo facecioso común.

1 Cf. ALBERTO DEI MONTE. Itinerario de la novela picaresca española. Barcelona, Lumen, 1971, p. 53. Y ss. 


\section{C) La nueva moral}

El gran pecado de Lázaro consiste, según Márquez Villanueva, en atentar contra el fixismo del orden estamental. La idea había sido, en realidad, anticipada por Bruce W. Wardropper, el cual ve reflejado en la novela el seamy side de la vida española del xvi ${ }^{1}$. En clla los valores morales aparecen invertidos: se equipara a la virtud con la mejora material -Lázaro, que, de entrada, confiesa no ser más santo que sus vecinos (Prólogo, 63), considera mucha virtud «saber los hombres subir siendo baxos" (Prólogo, 67) - y se identifica lo bueno con lo provechoso: "No mires a lo que pueden decir - recomienda el arcipreste- sino a lo que te toca, digo a tu provecho». "Señor, -contesta Lázaro- yo determiné de arrimarme a los bıenos) (VII. I44). Es la nueva mentalidad de la sociedad dineraria. Márquez entiende que el anónimo autor se opone decididamente a ella y, en consecuencia, castiga a Lázaro con el estrepitoso fracaso de su final. Los datos objetivos parecen confirmar tal apreciación. Ińn efecto si el oficio de aguador cra propio de moriscos y apenas si permitió a Lázaro, al cabo de cuatro años, mercar alguna ropa vieja, el de pregonero estaba considerado como infimo en la escala de los oficios reales y tampoco debía de permitirle gran holgura, cuando Lázaro se muestra satisfecho con que el arcipreste le de "en veces al pie de una carga de trigo, por las Pascuas su carne, y cuando el par de bodigos, las calças viejas que dexa...?" (VII. I43). Añádase a todo esto la infamante situación familiar... $\mathrm{Y}$, sin embargo, los datos objetivos quizás nos engañen. No se puede perder de vista la creencia común de que cualquier oficio real bastaba para dar honra. Lázaro afirma que "no hay nadie que medre, sino los que le tienen" (VII. I4I) y, en la Jornada I de la Seraphina, Lenicio dice a Floristán: "Señor, sernirte cobdicio; / pero ya sabes mejor / que para hazerse honor, / a un hombre basta un officio" (Gillet, II. I57). Pero hay más aún. "ILas conclusiones a que llega Lázaro después de su fatal encuentro con el toro de piedra -escribe Sicroff-, a saber, que él estaba sólo y que por sí mismo debe abrirse paso en el mundo, parece prefigurar la idea de que el yo es la única certidumbre» ${ }^{2}$. No se trata de una ideología sistemáticamente estructurada sino de la asimilación de una experiencia vivencial. Sobre esta base, F. Rico va mucho más allá e interpreta el Lazarillo como vertebrado por el subjetivismo relativista: «Es el yo quien da al mundo

1 El trastorno de la moral en "El Lazarillo". NRFH, I96I, XV, pp. 44I-447.

2 AI.BTRT SicRoFr, Sobre el estilo del "Lazarillo de Tormes*. NRFH, 1957. $\mathrm{XI}, 2$, pp. I 57-170. 
verdadera realidad; pero el yo es tan cambiante como el mismo mundo, por lo que no cabe deducir de él conclusiones de valor universal: tel relativismo en la axiología - concluye- es también un humanismon ${ }^{1}$. $\mathrm{Y}$, naturalmente, añado yo, una moral. Lázaro juzga y toma sus decisiones usccundum scipsunn: "Desquc me vf en hábito de hombre de bien, dixc a mi amo..." (V. I40); "Y vislo por mi que de tal persona (el arcipreste) no podía venir sino bien y favor, acordé... (VII. I42). El dato objetivo -que Lázaro también conoce- nos avisa, que el hábito es engañoso, que el arcipreste le engaña. Pero Lázaro juzga constituyéndose en norma de sí misno.

Resulta difícil completar la etopeya moral del protagonista. Si en el tratado I trasluce una conciencia y voluntad de perdón -nyo quisiera asentar mi corazón y perdonallen (I. 73) -, pocas páginas más adelante obedece a la ley del talión: "al avariento ciego y al malaventurado mezquino clérigo ...aquellos es justo desamarn (III. II5). Tiene conciencia de pecado en lo que se refiere a situaciones límite: «Maldíxeme mil veces (¿Dios me perdonc!)" (III. I08). Cuando miente, se disculpa con pretexto de honra o cortesía (III. I03). Por lo demás, todos los lugares en que atribuye formalmente los infortunios a sus pecados - hme toparon mis pecados con un clérigo" (II. 83), "quisieron mis hados, o por mejor decir, mis pecados" (II. 97), etc.- son topoi muy conocidos ${ }^{2}$. Idéntica condición tiene el calificativo "pecador», atribuído a personas — - hallé al pecador del ciegon (I. 76), uy yo, pecador, a llorarlas" (II. 98)...- cosas - (la pecadora del arca" (II. 95), "el pecador alfamar" (III. I27)- La mayor parte de referencias al demonio se inscriben casi siempre en el mismo catálogo de lexicalizaciones: considerado como tentador —-púsome el demonio el aparejo delante de los ojos" (I. 76)-, aludido en fórmulas de maldición - "daba al diablo el jarro y el vino (I. 72)- o, simplemente, como símbolo de maldad de una cosa: "dióme una gran calabazada en el diablo del toron (I. 67). Sólo en el tratado V aparecen upecado" y "denonion en su sentido propio. Márquez Villanueva considera a Lázaro $-\mathrm{y}$, en el fondo, al autor del Lazarilloespecialmente sensibilizados en materia de caridad, aunque, interpretando la novela como favorable a la tesis tradicionalista en la controversia sobre la mendicidad, el propio crítico se vea forzado a admitir que en este punto el autor se aparta de las progresistas directrices eras-

1 Francisco Rico, La novela picaresca y el punto de vista. Barcelona, Seix Barral, 1970, pp. $4^{I-55}$.

- Gustay Sumbman, Uber Sprache und Stil in Lazarillo de Tormes. Berna, r953, p. 8I y ss. 
mianas. A mí me parece absolutamente parcial contemplar sólo la falta de caridad de los amos y no reconocer la que Lázaro demuestra en la venganza del ciego o en el frío relato del fraude del buldero. Víctima de los propios avatares, Lázaro se ha hecho tan inmisericorde como sus amos. De otra parte, las referencias lingüisticas expresas a la falta de caridad -Sólo tres: "comigo tenía poca caridad» (II. 84), "porque la caridad se subió al cielo" (III. I02), "Cn este pueblo no había caridad" (III. II2) - responden a clisés tópicos. En la Sátyra de la Propalladia se lee: "¿Pues la caridad?. No ay d'ella memoria: / ni ay otra esperanza si de vanagloria" (Gillet, I. I58); idea que se repite en la Jornada III de la Calamita: "Ya sabes en quánta afrenta / y agonia / biuen los hombres oy día / en mundo tan sin bondad / que no ay en él caridad" (Gillet, II. 394).

En conclusión hay que decir que, visto objetivamente desde la perspectiva cristiana en cuya órbita social se mueve, Lázaro aparece al final de la novela como un cínico amoral, si bien esta actitud puede responder en él a una concicncia subjetivista práctica, compatible en la práctica con escasos y rutinarios vestigios externos - jel cngaño a los ojos! - de la moral tradicional.

En la cumbre de la buena fort una

Aunque en el Lazarillo no encontramos un desarrollo expreso del polémico tema de la fortuna ${ }^{1}$, se adivina en él el siguiente cañamazo dialéctico: A) La fortuna es parcial y caprichosa con los hombres (Prólogo 62). B) Con Lázaro, en concreto, ha determinado ser cruel; cuando el muchacho se percata de la situación real del escudero, exclama: "estuve en: poco de caer de mi estado, no tanto de hambre como por conocer de todo en todo la fortuna serme adversa" (III. IOS), y después: "quiso mi mala fortnna, que de perseguirme no era satisfecha..." (III. II6). C) I,a fortuna puede, sin embargo, ser vencida por la astucia y la ascesis del hombre y, en definitiva, por el poder de Dios. Lázaro relata su historia, precisamente, para que uvean que vive un hombre con tantas fortunas, peligros y adversidades" (Prólogo. 62) ${ }^{2}$ y para que se admire a los que, como él mismo, "siéndoles contraria, con fuerza (=as-

I Una clara exposición de la trayectoria histórica de la controversia puede verse ell ERna Rutin Barndi, Amor, muevie y fortuna en "La Celestina". Madrid, Gredos, I963, pp. II7-I78.

2 "Fortunas" significa aquí "desgracias». Cf. GILLET, III, p. I92, núm. 552. 
cesis) y maña (=astucia) remando, salieron a buen puerto» (Prólogo. 62). Hacia éste le ha guiado su Dios. Ahora, al poner punto final a su carta autobiográfica, el año ell que unuestro victorioso Emperador en esta insigne ciudad de Toledo entrón' ${ }^{2}$, Lázaro se encuentra en prosperidad y cil la cumbre de toda buena fortunan (VII. I45).

Conclusiones

El cotejo detenido del Lazarillo con una serie de obras de la época que el anónimo autor debió, sin duda, leer, permite fijar las siguientes conclusiones:

I. El núcleo argumental de la novela e, incluso, su planteamiento desde la perspectiva del marido complaciente, tienen un marcado carácter tópico, que obliga a descartar una especifica intención religiosa inicial, de signo eramista-iluminista o judaizante.

2. In una larga tradición literaria, que va desde La Celestina a obras tan dispares como La Lozana Andaliza o el Viaje de Turquia, se inserta, también la figura de un Dios "ad usum», coadjutor de Lázaro en el bien y en el mal. No puede, por tanto, verse en ella una critica de la fe práctica de los cristianos viejos.

3. Las referencias expresas de Lázato a la oración y su vivencia de la misma contradicen la pretensión de ver en él a un cristiano espiritual e interior, opuesto críticamente por el autor a la mayoría religiosa oficial del país. Es clara, desde luego, la denuncia de una falsa devoción —el engaño a los ojos-, apreciable en el mendigo, el hidalgo y el buldero. Pero hay que notar que el propio Lázaro incurre en ella al servicio de sus intereses.

4. Ni la afirmación "muy devotamente le ví oir missa", ni el episodio del arca ui el mismo juramento usobre la hostia consagradan auto-

1 Constituye un topos el relaciouar la anécdota biográfica degradada con um hecho histórico sobresaliente. Asi, Divicia, cortesana amiga de La Lozana, dice: "Por cierto que pasó, que cuaudo vino el rey Carlo a Nápoles, que comenzó el mal incurable el año de mil y cuatrociento y ochenta y ocho, vine yo a Italian (La Lozana. LIII. 202) y la propia Aldonza hace un chiste celebrando rel arte de aquella mujer que fue en Salamanca en tiempo de Celestino segundon (Dedicatoria. 33). No prejuzgo con esto las reivindicaciones de la segunda parte del Lazarillo (Cf. RICHARD E. ZwEz, Hacia la revalorización de la Segunda Parte del Lazarillo (1555). Albatros Ediciones. 1970) o del Tratado VII de los Tedescos (Cf. El Tratado VIII del Lazarillo, en. CARLos RIPOLI, La Celestina a través del Decálogo. $Y$ otras notas sobre la Litcratura del Siglo de Oro. Las Américas Publishing Counpany, 1969, Pp. I26-194). 
rizan para acusar a Lázaro de falta de fe eucarística. Se trata, en efecto, respectivamente, de un dato de observación, de una parodia comunisima en la época y de una fórmula igualmente usual que utilizan los mismos inquisidores. Contra lo que generalmente se afirma, el empleo de los nombres de Cristo y la Virgen en la literatura de la época era más bien escaso. Iâl de Dios, muy frecuente, aparece utilizado en sentidos plurivalentes.

5. El cotejo particularizado de los rasgos anticlericales del Lazarillo con los de la literatura de la época viene a confirmar la tesis de Bataillon de que nada añaden a la tradición medieval de los fabliaux. Por lo demás, hay que notar que la sátira no alcanza en la. novela más que a los bajos estamentos del clero, en tanto que la crítica heterodoxa apuntaba más bien a prelados y dirigentes.

6. Sin descartar la posibilidad de interpretar el final del Lazarillo como un castigo de la rebeldía progresiva de Lázaro frente a la sociedad estamental, parece más coherente con el desarrollo de la obra ver en él la encarnación de una nueva moral, relativista y subjetiva.

VICTOR G. DE IA CONCHA

1 En prensa este artículo aparece un estudio importantísimo de Alberto Blecua, Libros de caballerias, latin macarrónico y novela picaresca: la adaptación castellana del Baldus (Sevilla, I542). BRABL, XXXIV, I97I-I972, pp. I47-239. Remito a él al lector interesado en el problema de la tradición y originalidad del Lazarillo. 